\title{
Contemporary technological development and challenges to the international humanitarian law
}

\author{
Mohammad Saidul Islam \\ Department of Law \\ International Islamic University Chittagong, Bangladesh
}

\begin{abstract}
International Humanitarian Law (IHL), is an important branch of the public international law, it does not speak about the lawfulness of armed conflict, it seeks instead to protect the civilians and hors de combats through imposing limitation to the freedom of the choice of the weapons and strategies of warfare. The development of science and technology has significantly changed the nature of weapons and war strategies and complicated the implementation of IHL. This article describes the technologically developed new weapons and methods which are randomly used in the contemporary armed conflict. This paper also focuses on the new challenges faced by the frequent use of technologically advanced weapons in the modern armed conflict.
\end{abstract}

Keywords International humanitarian law, Implementation, Means and methods, Warfare, Drone, Cyber attack

Paper type Literature review

\section{Introduction}

At the outset, I have to state the obvious: the implementation of IHL, like all of international law, is threatened by ignorance, manipulation, unwilling of the state parties, misinterpretation of the treaty provisions and so on. In addition to these, the advances of technologies have also created some new problems to the implementation of IHL. The $20^{\text {th }}$ and $21^{\text {st }}$ centuries observed the use of many new weapons and military strategies in the armed conflict namely the automated weapons, autonomous weapons, drones, cyber warfare which eroded the protection of the protected persons and objects namely civilians and their objects (Schmitt et al. 2004).

The Unmanned Ariel Vehicle commonly known as

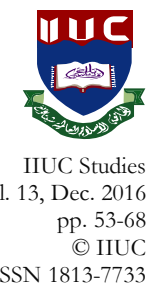




\section{IIUC STUDIES, 13}

drone was, although, first deployed for surveillance and reconnaissance purposes in 1960s, later on over the last ten to fifteen years, it was used on a significant scale for military and counter-terrorism purposes with insignificant consideration to the rules of jus ad bellum and jus in bello (Maslen 2012:598). Another new big field of conflict is the virtual world where in the cyber attack the rules of IHL are frequently neglected. The other novel weapons namely automated, autonomous weapons, chemical and nuclear weapons which are indiscriminate in nature are also recent threat to the implementation of international humanitarian law (Schmitt et al. 2004). It focuses the developments and uses of new weapons and methods namely drones, autonomous and automated weapons, chemical weapons and cyber warfare in the international armed conflict (IAC) and non-international armed conflict (NIAC) by state or individual or nonstate actors. This paper also highlights the peremptory challenges to the international humanitarian law regarding implementation and application.

\section{Technologically Advanced New Means of Warfare}

The interaction between the development of technology and the nature of conflict is a constant history of war. From time immemorial the States and its military forces have responded to the developments of science and technology by adopting new weapons in the armed field (Stewart: 271). Once in the armed conflict the weapons namely sword, knive, axe, sickle, bow and arrow were used by the parties, the gradual development of science and technology has changed these types of weapons. The $20^{\text {th }}$ century and in particular $21^{\text {st }}$ century have revolutionized the warfare by new technologies and new weapons. Boothby (2014:22) states among the various types of new means of warfare the most frequently used weapons and methods in the recent past are the cyber warfare, remote controlled weapons systems (drones), chemical and biological weapons and so on. Some other weapons which are yet to be invented but under horizon namely nano-technological weapons, fully autonomous weapons and artificial intelligence would be the worst contribution of the technology in the war. These new technological weapons can be categorized in the following ways:

1. Existing new technological weapons

2. Futuristic technological weapons

\section{Existing New Weapons}

A good number of new weapons are already in use in both IAC and NIAC namely the remote controlled weapons systems, automated 
weapons, cyber warfare, unmanned technological weapons and biological, radiological and chemical weapons and so on. It is not evident whether these weapons have been developed complying with the obligations imposed under article 36 of the Additional Protocol (AP) I. It is clear that the recent use of them in the armed conflicts have frequently violated the rules of IHL. This article is an effort to focus on what and how the newly developed weapons have sophisticated the application and implementation of IHL in the armed conflict.

\section{Remote Controlled Weapons Systems (RCWSs)}

Remote Controlled Weapons Systems or Drone, an unmanned Ariel vehicle, was initially used to train the military personnel for target practice, later on it moves to use for targeted killing in and outside of the armed conflict (Ian 2014). In 1959 the U.S. Air Force began planning to use unmanned aircraft as they were losing their pilots over hostile territories. In the next year they launched a highly classified unpiloted aerial attack over the Soviet Union under the code name "Red Wagon" (Wagner 1982: 11-12). The first modern battle field unmanned aircraft called Tadiran Mastiff was invented by Israel in 1973 with the capacity of good endurance for loitering and live video streaming. The United States of America also used UAVs in 1973 in Vietnam and during the war approximately 3435 UAVs missions were flown by USA (Cai \& Geng, 2015:1921). Over the last decade a considerable number of drone attacks were carried out by many states particularly USA in different areas of the world especially in Pakistan and Afghanistan for targeted killings and ultimately killed many civilians including children and women.

A top controversial newly developed weapon system the drone which at the time of hovering over the targeted person or thing, takes picture of them and sends back it to the controlling authority remaining far away from the combat zone then the crew at base after analyzing the picture either commands for attack or returns the drone without attacking. Drone, although, an unmanned vehicle but not unpiloted, after taking the picture of the targeted person or thing sends it back to the steering crew who analysis the images and commands for further actions on the basis of the pictures what are seen from far away (BBC News, 2012). Kellenberger (2011:3) sates that the RCWSs or drones are an advance move to conduct attacks on the enemies keeping the combatants long away from the adversaries and the battle field. Initially it was used for intelligence, surveillance and reconnaissance (ISR) purposes during armed conflict, for example, in the Vietnam War the drone was used for reconnaissance purpose (Schamitt 2011:313). Later on it is used to attack 


\section{IIUC STUDIES, 13}

the targeted persons or objects from considerable distance. In this system the soldiers stay in a far away from the actual combat zone which keeps them away from the real casualties. As an unpiloted aerial vehicle or remote controlled weapons system "Drone" is the mostly used weapons in the recent past.

Various types of drones have already been invented by many countries. Among them most common ones are the RQ-11B Raven, the RQ-4 Global Hawk, mainly used for surveillance and reconnaissance functions and the Predator and the Reaper, are used for armed attack (Schamitt 2011: 313-14). The RQ-11B Raven is a mostly used drone operated by two persons either manually or autonomously in prior settled route (Factsheet-RQ11B Raven, 2010). The RQ-4 Global Hawk is a high-altitude and long endurance ISR drone operated by three crew far from the battlefield (Factsheet-RQ-4 Global Hawk 2009). It has the superior intelligence and surveillance collection capability which allows the precise attack on the targeted persons or things. On the other hand the most prominent armed drone, the Predator, in compare with Global hawk, is a medium altitude but long endurance drone used for many purposes namely reconnaissance, intelligence, surveillance, route cleaning, combatants searching, rescuing, close air support, air interdiction and so on (Factsheet-MQ-1B Predator 2010). Another important armed drone is the MQ-9 Reaper, a medium-to-high altitude MQ-9 Reaper is mostly relied on for conducting attacks on the targeted persons and objects. Over 1,000 nautical miles range Reaper drone has become popular to the world for its ability to stay aloft for longer periods (Factsheet-MQ-9 Reaper 2010). Now different types of drones are used for targeted killing in many parts of the globe.

\section{Computer Based Information Warfare}

Computer based information warfare or cyber warfare was a new concept in the 20 century but now it is common to the world communities for its random use by States or individuals or non-state actors. Usually cyber warfare is different from the traditional war as it is held in the virtual world but its impacts occur in the real world which may be more dangerous and devastating in many cases in compare to kinetic war.

This computer based information warfare or the cyber warfare has been defined by Rose (2010) as the Cyber warfare which indicates an online based conflict where the state or individual groups being politically motivated attack on information or information system of the enemy state. US Department of Defense (2010) states cyber operations are committed by a computer against a computer or computer system 
through a data stream. Such attacks can cause severe damage and grave harm to many installations, industries, telecommunications, financial systems and so on.

\section{Automated Weapons}

The development of automated weapons is not so old. It is one step advance technology from the remote controlled weapons systems. The automated weapons are different from the remote controlled weapons systems in this sense that the latter is controlled by human being staying in remote places; on the other hand once the automated weapon is deployed it functions in a self-contained and independent manner, for instance, automatic fire arms, certain landmines, automated sentry guns etc.

Among the automated weapons Landmine is well known and most used weapon across the globe. Landmine is explosive device which is designed in such a way that it automatically blasts or blows when triggered by pressure. These devices are basically set up just below the surface of the ground to disable the pedestrians or vehicles which come into the contact of it by explosion or fragments. The innocent children and women are the main victims of this weapon (Kevin 2001). Human Rights Watch (2015) mentions that antipersonnel landmines are weapons of indiscriminate nature which cannot make a distinction between a civilian and a soldier resulting to killing and maiming of the civilians who step on them or pick them up. For its inherent indiscriminate nature its production, stockpiling, usage and transferring have been fully banned by Mine Ban Treaty (art. 1(1) of the 1997 Mine Ban Treaty). Even the states who have stockpiled these weapons are asked to destroy them immediately and they are also required to clean the mined areas for safety of the people as well as to assist landmine survivors. Not only land mines, other automated weapons also are indiscriminate in nature and any weapon which is indiscriminate is fully prohibited under the international humanitarian law, although the world communities are more interested to develop more automated weapons for its safetiness, cost effectiveness and effectiveness in the armed field.

\section{Nuclear Weapons}

The most devastating inherently indiscriminate weapon is the Nuclear Weapon. The world has already bitterly tested the effects of Nuclear Weapons in 1945 when USA attacked Nagasaki and Hakaluki of Japan. The highly destructive potential weapon of the globe 'Nuclear weapon' refers to weapons which provide destructive energy through nuclear reactions of fusion or fission or a combination of fusion and fission (Loye 


\section{IIUC STUDIES, 13}

\& Robin 2007). It is considered as the most devastating weapon in the human history of warfare. After a nuclear explosion it causes injury to human being in many ways, for example, emission of thermal (heat) radiation causing a large-scale firestorms resulting to burnings and other severe injuries, radiation and radioactive fallout causing radiation sickness (Loye \& Robin, 2007:334). As of 2016, two nuclear weapons, 'Little Boy' and 'Fat Man', were used in the history of nuclear war by the United States of America consecutively on $6^{\text {th }}$ and $9^{\text {th }}$ August 1945 near to the end of the World War II, over the Japanese city of Hiroshima and Nagasaki. Radiation Effects Research Foundation (2007) released a report that approximately 200,000 people both civilians and military personnel lost their life as the consequences of the nuclear expulsion in Japan. A 2001 joint study of the scientists of United States and India on effects of nuclear explosion revealed that only five nuclear weapons explosion in Pakistan Cities and five in India would result the deaths of 2.9 million people and 1.5 million severely injured (Matthew G. Mc Kinzie, Zia Mian, A. H. Nayyar \& M. V. Ramana, 2001). Considering its highly devastating nature, immediately after the end of the World War II, initiative was taken to negotiate a treaty and finally the Nuclear Test Ban Treaty was signed in Moscow, Russia on August 5, 1963, with a view to reducing and banning the nuclear weapons. This object has been partially achieved as the global inventory of nuclear warheads has been significantly reduced from an estimated 70,300 to 15,400 but the number of nuclear weapons owner countries has increased from three to nine namely the United States of America, the United King Doom, Russia, China, India, Pakistan, France, Israel and North Korea (Hans M. Kristensen \& Robert S. Norris, 2016). The existing nuclear weapons and the trend to be owner of nuclear weapons by the State are the continuous threat to the peaceful human existence. Today approximately 1800 US, Russian, British and France nuclear warheads are still deployed and ready for use at short notice.

\section{Chemical Weapons}

Another weapon which is commonly used in the armed conflict is 'Chemical weapons' means a toxic chemical including nerve, blister, choking and blood agents and it indiscriminately causes incapacitation, serious bodily harm or injury or even death also. The simplicity of its use made its application high in the armed conflict. It can be released only by piercing the container containing chemical weapons or by simply placing a container of chemical next to an explosive charge (Loye \& Robin, 2007:338). Although the use of chemical weapons to suppress the rebels or to defeat the enemy of the armed conflict is not a new method, the 
rapid and frequent use in the recent conflict seriously concerns the world communities. The Washington Post (2013) reported that in the Syrian conflict, the government forces used huge amount of chemical weapons against the rebels to take the control of the strategically valuable territory where they failed to hold their control despite the use of many weapons, i.e., heavy artillery barrages what resulted huge number of civilians' casualties, more than 1400 deaths. Ali (2001:43) mentions that the use of chemical weapons by the both sides in the war between Iraq and Iran during the 1980-1988 inflicted huge human costs. Ali (2001:43) states, "from the Global perspective, the use of chemical weapons by Iraq and allegedly by Iran demonstrated that third world weapons of mass destruction where the proliferators can easily generate significant tactical military and strategic political benefit from the use of such weapons." Chemical Weapons Convention Bulletin (1995:20) in a report mentions that during Iraq-Iran war between 500000-600000 casualties held related to chemical weapons and another report released by Iran March, 1995, revealed that up to 60000 veterans of this war were admitted to the Kowsar Health Complex in Tehran who were injured by the chemical weapons attacks of Iraq. The most extensive use of chemical toxic in the battle space observed by the world was the World War I where more than one million chemical weapons related casualties had occurred (Fredrick, Eamest \& Dacid, 1997:27).

A good number of conventions, treaties and protocols have been adopted from and before the World War I to till 2015 banning the use, production and proliferation of the chemical weapons. In 1899 The Hague Regulation and most importantly the Geneva Protocol of 1925 has made strict rule against the use of both chemical and biological weapons. The Geneva Protocol prohibits the use of chemical weapons in the warfare but it did not prohibit the production, development, research, storage, testing and stockpiling the chemical gas. But the recent important document the Chemical Weapons Convention 1992 clearly prohibits the use, development, production, stockpiling and its destruction.

\section{Futuristic Technological Weapons}

The developed countries especially USA and Russia have planned to invent in near future some weapons namely autonomous weapons for using in the battle field. Among them the top most controversial weapon which is yet to be in use is the fully autonomous weapons. 'Autonomous Weapon System' which can target and initiate the use of potentially lethal force without direct human supervision, control and involvement in lethal decision-making. 


\section{IIUC STUDIES, 13}

The US Department of Defense Directive (2012, pp. 13-14) considers "a weapon system to be autonomous if, once activated; it can select and engage targets without further intervention by a human operator." According to the UN Special Rapporteur on extrajudicial, summary or arbitrary executions, "Lethal Autonomous Robotics (LARs) refers to robotic weapon systems that, once activated, can select and engage targets without further intervention by a human operator. The important element is that the robot has an autonomous 'choice' regarding selection of a target and the use of lethal force." It can sufficiently be defined that "autonomous weapon" that acts independently in "engagement-related functions" for example, the acquisition, tracking, identification, grouping, selection, prioritization and engagement of targets. Each step in this socalled "kill chain" or "loop" involves functions which the weapon system might fulfil autonomously. If any of these functions are autonomous, the weapon system may be classified as an Automated Weapons, and if all of them are autonomous, the system is a fully autonomous weapon (FAW) (Gubrad \& Altmann, p.2). For example, the PHALANX system used by the US Navy is able to autonomously detect, track, and fire at anti-ship missiles (United Nations Navy Fact File, 2012).

The aforesaid discussion demonstrated that the drones, mines, chemical weapons, cyber attacks and autonomous weapons are the technologically advanced means and methods of warfare which are now commonly used in both IAC and NIAC by States and non-sate actors and the fully autonomous weapons which are yet to be invented but under plan. Now this article highlights how these weapons have complicated the implementation of IHL in the contemporary armed conflict.

\section{New Weapons and Strategies of Warfare and Challenges to IHL}

The rapid development of science and technology in the $21^{\text {st }}$ century poses a multiple challenges towards the implementation of the IHL in both national and international armed conflict. The various arms and tactics of war, i.e. drones, mines, autonomous weapons and cyber warfare, which are commonly used in the contemporary armed conflict, are creating many complexities to the implementation of the international humanitarian law. The aforesaid analysis has shown the technologically developed new means and methods of warfare. It now explores to present how these means and methods are the new challenges in the implementation of IHL.

For the implementation of IHL it is compulsory to the parties of the conflict that they must comply with the principles of IHL during the armed conflict. As article 48 of AP I imposes a stringent obligation on the 
parties to a conflict that they must distinguish civilians from combatants and civilian objects from military objectives and accordingly conduct their military operations only against military objectives. And article 51 sets out the general premise that "civilians enjoy general protection against dangers arising from military operations" so the military actions, "the primary purpose of which is to spread terror among the civilian population" are always prohibited (Art. 51, AP 1, 1977). A fundamental element of the principle of distinction is that "in the conduct of military operations, constant care shall be taken to spare the civilian population, civilians and civilian objects" (Art. 57.1, AP 1). It also elaborates the principle of proportionality by reference to "expected incidental loss of civilian life, injury to civilians, damage to civilian objects," it was reiterated in articles 51.5 (b) 57 (2) (a) (ii) \& (b) of AP 1. During armed attacks, the principle of precaution as mentioned in article 57 of AP I requires the parties to select those methods, and means of warfare which minimize "incidental loss of civilian life, injury to civilians and damage to civilian objects," and also seeks to send a prior warning if the attack has any possibility of "affect the civilian population" (57.2. c of AP 1), and choosing targets may cause "the least danger to civilian lives and to civilian objects (57. 3 of AP 1)." In aerial and naval operations, the parties must take all reasonable precautions "to avoid losses of civilian lives and damage to civilian objects (57.4 of AP 1)." These are the fundamental principles of IHL in brief which a State is required to comply during armed conflict to choose the means and methods of warfare. The newly developed weapons and strategies cannot be applied in the armed conflict maintaining these principles which can be evident from the following analysis.

The big challenge to implement IHL is the use of remote controlled weapons namely drones in the armed filed and out of armed conflict. Now the most used weapon the unmanned Ariel vehicle or drone which has both positive and negative consequences in the battle field but mixed reactions of the people. The statistic shows that drones attacks over the last decade have fully failed to maintain the principles of IHL. As David \& Mc Donald, (2009) wrote "in The New York Times in March 2009, relying on statistics provided by Pakistani sources, that the U.S killed 50 unintended targets for each intended target". Another picture of drone attack is after the killing of Mehsud, Jane Mayer in the New York wrote that the $6^{\text {th }}$ August attack against Baitullah Mehsud was the sixteenth UAVs attack where as previous fifteen were unsuccessful to kill him which resulted to kill between 207 to 321 civilians (Jane 2009).

The second big problem of drone use is that the drone attacks are operated by non-combatants but in an armed conflict only the combatant 


\section{IIUC STUDIES, 13}

has the right to directly participate in the hostilities as Article 43(2) of Additional Protocol I states, "members of the armed forces of a Party to a conflict (other than medical personnel and chaplains covered by Article 33 of the Third Convention) are combatants and they have the right to participate directly in hostilities". Except combatant no one has right to participate in the armed conflict and if any one participates that is violation of IHL. The drone attacks by USA in Pakistan, Afghanistan are conducted and regulated by CIA that is not the part of armed forces of USA (non-combatant) which is also clear violation of IHL. So it is clear that the targeted killing by the drone attack has failed to maintain the principles of IHL, so it is urgent need to consider the effects of use of the drone in and outside of the armed conflict.

Today the main concern of the world communities is the cyber attack. In cyber attack it is quite impossible to maintain the principle of distinction and proportionality. For instance, a cyber attack against an air traffic control system would indiscriminately affect both the military and civilian aircraft or an attack on a dam would cause the release of plenty of water causing damage to the property of both civilians and military and endangering the life of civilians and combatants also. In both of these cases it is not possible to maintain the principles of IHL.

Another concern in cyber attack is that in cyber operation it may be possible to indentify that from what country and from what computer the attack was committed but it is not possible to identify the person who committed the attack. For example a Chinese citizen after coming Bangladesh may cause cyber attack against India. If the perpetrator of this attack is searched then it will be found that someone from Bangladesh and by Bangladeshi computer committed this cyber attack as a result Bangladesh is liable for this attack but reality is Bangladesh has no involvement in this attack. So this uncertainty of the identity of the originators of the operations poses a big challenge to the implementation of IHL. As regarding cyber attack against Estonia, the operations were traceable to Russia but it could not certainly be told that Russian government had conducted the operation as there was no conclusive evidence (Schmitt, 2011).

Another big question on the cyber warfare is whether IHL is applied in the cyber warfare. There is no clear provision in any national or international instruments regarding application of IHL in the cyber warfare. In absence of any clear provision in the Geneva Conventions of 12 August 1949 and its Additional Protocol 1977, by a wider interpretation of the articles of the Conventions and Protocols it can be said that international humanitarian law is applied both in International 
and Non- International Armed Conflict. This lack of evident provision on the application of IHL in the cyber attack encourages the attackers to make more cyber attacks and makes a grave problem to implement international humanitarian law in the cyber warfare.

On the other hand the automated weapons i.e. mines, chemical and nuclear weapons are indiscriminate in their nature as a result they are prohibited from the very beginning. Because these weapons cannot be used maintaining the principles of IHL, it is not for negligence of the parties but for the indiscriminate nature of the weapons. For instance the chemical weapons cannot be used only for the combatants if it is used it will do harm both for the civilians and combatants. If a mine is set up in a place then it will blast if pressure is given on it here it is not the matter of consideration who has pressured on it civilians or combatants, male or female, minor or major and if an atom bomb is thrown in any city or place it will kill both civilians and combatants.

It is matter of grave concern that the futuristic weapons namely the fully autonomous weapons if developed and used in the armed conflict then it would complex the application of the principles of IHL. Noel Sharkey comments that "no autonomous robots or artificial intelligence systems have the necessary skills to discriminate between combatants and innocents". The use of autonomous weapons can generate the following challenges regarding the application of IHL:

1. As the autonomous weapons are sensor based weapons which can operate themselves without any control of human being so they cannot discriminate between military objectives and civilian objectives.

2. A difficulty may arise regarding the identification of the perpetrators behind the deployment of the autonomous weapons.

3. The autonomous weapons itself is able to take decision and significantly influence the decision, but this decision making capability of a weapon is not accompanied by either responsibility or accountability like human being may cause a big problem to comply with the rules on the conduct of hostilities (Liu, 2013: 632).

4. Another debateable question is raised whether the FAW is able to distinguish between two persons one who is digging a trench from a member of armed conflict and another that member of armed forces who is planting an improvised explosive device (Chantal, 2013: 10). 


\section{IIUC STUDIES, 13}

After this short analysis it can be concluded that the fully autonomous weapons are unable to follow the principles of IHL so this short write up calls upon the world communities to take an effective initiative for banning the development, production and use of these weapons.

\section{Findings}

The article found that the science and technology have highly contributed to invent some new weapons and methods which are now chosen by the parties to combat the enemy opponent. These weapons and methods include remote controlled weapons systems namely drone, chemical, nuclear and automated weapons, i.e. mines, automatic fire arms, automated sentry guns and cyber warfare. The study also found that fully autonomous weapon is, for example robot, yet to be invented but relentless effort is given by developed countries to deploy this weapon in near future.

The study further found that the use of these weapons and methods in the armed conflict are the big challenges to implement IHL during the armed conflict. These weapons and methods cannot be used in the armed conflict maintaining the provisions of Geneva Conventions and its Additional Protocols. These weapons are mainly indiscriminate in nature so its use in the armed conflict causes havoc damages and deaths to the civilians, hose de combats, and civilian property and objects.

\section{Conclusion:}

Many weapons, i.e., the chemical weapons, various mines, nuclear weapons and so on, have already been prohibited by international conventions, treaties and national legislations. Yet some of these are randomly used in the national and international armed conflicts namely chemical weapons, mines. Some other means and methods of warfare, for example, cyber warfare, drones attacks, which are big threat for human being and challenge to the international humanitarian law yet to ban by adopting any specific international convention and protocol.

The autonomous weapons which are under process need to ban before the invention. The use of the autonomous robots in the armed field is the great threat to the whole human and IHL. On the other hand the autonomous weapons are inherently indiscriminate which is prohibited under the Additional Protocol I. Although the autonomous weapons cannot be used lawfully under the existing provision of IHL yet its research, development, improvement experiment and transfer must be banned by making separate convention and protocol before coming into existence. 


\section{Contemporary technological development 65}

The automated weapons especially drones can be used in the armed field and in the rescue operations in the remote area and in natural disaster, after taking utmost care and sincerity but in no case out of the armed conflict for killing the targeted persons.

In the conclusion it can be said that according to article 36 of the AP I, "in the study, development, acquisition or adoption of any weapons, means or methods of warfare, a high contracting party is under an obligation to determine whether its employment would, in some or all circumstances, be prohibited by this protocol or by any other rule of international law applicable to the high contracting party" (Art. 36, AP 1).

So if a state intends to develop any new weapons then it needs to consider whether it can be used complying with the principle of IHL if it cannot be done then that State should not develop that weapons and use it in the battle field.

\section{References}

Schmit, M. N (2013) (ed.) Rule 13, Tallinn Manual on the International Law Applicable to Cyber warfare. Cambridge University press, prepared by International Group of Experts at the invitation of NATO Cooperative Cyber Defence Centre of Excellence.

Ali, J. (2001). Chemical weapons and Iraq-Iran war: a case study in noncompliance.The Nonproliferation Review, 8(1), 43-58.

BBC News, South Asia. (2012). Drones: what they are and how do they work? Retrieved January, 2017 from http://www.bbc.com/news/world-south-asia10713898

Boothby, H. W. (2014). The legal challenges of new technologies: an overview. In H. Nasu,\& R. McLaughlin. (Ed.), New Technology and the Law of Armed Conflict, (pp. 22).

Cai, H., \&Geng, Q. (2015). Research on the development process and trend of unmanned aerial vehicle. International Industrial Informatics and Computer Engineering Conference.

Chantal, G. (2013).The challenges of autonomous lethal robotics to international humanitarian law. Journal of Conflict and Security Law, Oxford University Press.

Chemical weapons Convention Bulletin, (June 1995). See also, jannys, S. (1991). Iranian veterans suffer chemical weapons chilling effects. Los Angeles Times.

Christof, H. (2015). UN report of the special rapporteur on extrajudicial, summary or arbitrary executions. United Nations General Assembly. doc. $\mathrm{A} / \mathrm{HRC} / 23 / 47$. 


\section{IIUC STUDIES, 13}

David, K., \&Mcdonald, A. E. (2009, May 17). Death from above, outrage down below. N.Y.TIMES. Retrieved from http://www.nytimes.com/2009/05/17/opinion/17exum.html?_r=1\&scp=1 \&sq $=$ death $\% 20$ from $\% 20$ above $\% 20$ outrage $\% 20$ from $\% 20$ below\&st

Factsheet-MQ-1B Predator. (2010). United States Air Force. Retrieved from http://www.af.mil/information/factsheets/factsheet.asp?fsID=122.

Factsheet-MQ-9 Reaper, (2010). United States Air Force. Retrieved fromhttp://www.af.mil/information/factsheets/factsheet.asp?fsID=6405.

Factsheet-RQ11B Raven. (2010). United States Air Force. Retrieved fromhttp://www.af.mil/information/factsheets/factsheet.asp?fsID=10446.

Factsheet-RQ-4 Global Hawk. (2009). United States Air Force. Retrieved from http://www.af.mil/information/factsheets/factsheet.asp?fsID=10446.

Fredrick, S., Earnest, T., \& David, F. (1997). Medical aspects of chemical and biological warfare. Walter Reed Army Medical Center, Washington D.C.

Gubrad, M., \& Altmann, J. Compliance measures for autonomous weapons convention; ICRAC Working Paper. International Committee for Robot Arms Control.

Hans, M. K., \& Robert S. N. (2016). Status of world nuclear forces. Federation of American scientists (FAS). Retrieved May 2018from http:/ fas.org/issues/nuclear-weapons/status-world-nuclear-forces/

Human Rights Watch Report (2015). Landmines. Retrieved from https://www.hrw.org/topic/arms/landmines.

Ian, G. R. S. (2014). The rise of the predator empire: tracing the history of U.S. Drones. Understanding Empire. Retrieved from https://understandingempire.wordpress.com/2-0-a-brief-history-of-u-sdrones/.

Jane, M. (2009). The predator war: what are the risks of the C.I.A.'s covert Drone program? The New Yorker. Retrieved from http://www.newyorker.com/reporting/2009/10/26/091026fa_fact_mayer.

Kellenberger, J. (2011). International humanitarian law and new weapon technologies. $34^{\text {th }}$ Round Table on Current Issues of International Humanitarian Law, San Remo. Retrieved from

http://iihl.org/iihl/Documents/JKBSan\%20Remo\%20Speech.pdf

Kevin, B. (2001). How Landmines Work. Retrieved May, 2015fromhttp://science.howstuffworks.com/landmine.htm

Liu, Y. H. (2013). Categorization and legality of autonomous and remote weapons systems. International Review of the Red Cross, 94(886). 


\section{Contemporary technological development 67}

Loye, D., \&Coupland, R. (2007). Who will assist the victims of use of nuclear, radiological, biological or chemical weapons - and how? International Review of the Red Cross, 89(866).

Maslen, C. S. (2012). Pandora`s box? Drones strike under Jus ad Bellum, Jus in Bello and international human rights law. International Review of the Red Cross, 94(886).

Matthew, G., McKinzie, Z. M., Nayyar, A. H., \&Ramana, M. V. (2001). The risk and consequences of nuclear war in South Asia. In Smitu, K. \& Zia, M.(Eds.), Out of the Nuclear Shadow. New Delhi: Rainbow Publishers.

O Connel, E., \& Merry. (2010). Unlawful killing with combat drones a case study of Pakistan 2004-2009. Legal Studies Research Paper. Notre Dame Law School.

Radiation Effects Research Foundation.(2007). Frequently Asked Questions I; How many people died as a result of atomic bombings. Retrieved January 2018from http://www.rerf.or.jp/general/qa_e/index.html

Rose, M. (2010). What is Cyber Warfare.Tech Target Search Security. Retrieved September 15, 2013 from http://searchsecurity.techtarget.com/definition/cyberwarfare

Schmitt, M. N. (2011). Drone Attacks under Jus ad Bellum and Jus in Bello: Clearing the 'Fog of Law. Yearbook of International Humanitarian Law, 13, 311326.

Schmitt, M. N. (2011). Cyber Operation and Jus in Bello: Key Issue. Naval War College International Law Studies. Retrieved from http://ssrn.com/abstract $=1801176$

Schmitt,M. N., Harrison, D., \& Heather, A. (2004). Computer and war: the legal battle space. International Humanitarian law Research Initiative, Program on Humanitarian Policy and Conflict Research at Harvard University 1033 Massachusetts Avenue Fourth Floor Cambridge, MA 02138. Retrieved from www.hsph.harvard.edu

Stewart, M. D. New Technology and Law of Armed Conflict. International Law Studies, 87.

The US Department of Defense, Directive 3000.09, (November 21, 2012).

The Washington Post. (August 30, 2013). More than 1400 killed in Syrian chemical weapons attack. Retrieved from http://www.washingtonpost.com/world/national-security/nearly-1500killed-in-syrian-chemical-weapons-attack-us-says/2013/08/30/b28646621196-11e3-85b6-d27422650fd5_story.html

United States Navy Fact File. (2012). MK 15 - Phalanx Close-In Weapons System (CIWS). from http://www.navy.mil/navydata/fact_display. 


\section{IIUC STUDIES, 13}

asp?cid $1 / 42100 \& \operatorname{tid}^{1 / 4} 487 \& \operatorname{ct}^{1} / 424$, referred from Chantal, G. .(2013). The Challenges of Autonomous Lethal Robotics to International Humanitarian Law, Journal of Conflict and Security Law, Oxford university Press.

US Department of Defense, Dictionary of Military and Associated Terms, 8 November 2010 (as amended on 31 January 2011),Washington, DC, 2010:

Wagner, W. (1982). Lightning bugs and other reconnaissance Drones; The can-do story of Ryan's unmanned spy planes. Armed Forces Journal International.

\section{International Instruments}

Convention on the Prohibition of the Use, Stockpiling, Production and Transfer of Anti-Personnel Mines and on their Destruction 1997, adopted $3^{\text {td }}$ December 1997, effective on $1^{\text {st }}$ March 1999

Geneva Convention (I) for the Amelioration of the Condition of the Wounded and Sick in Armed Forces in the Field of 12 August 1949, 75 UNTS 31 (entered into force 21 October 1950).

Geneva Convention (II) for the Amelioration of the Condition of the Wounded and Sick and Shipwrecked Members of Armed Forces at Sea of 12 August 1949, 75 UNTS 31 (entered into force 21 October 1950).

Geneva Convention (III) Relative to the Treatment of Prisoners of War of 12 August 1949, 75 UNTS 31 (entered into force 21 October 1950).

Geneva Convention (IV) Relative to the Protection of Civilian Persons at Time of War of 12 August 1949, 75 UNTS 31 (entered into force 21 October 1950).

Protocol Additional to the Geneva Conventions of 12 August 1949, and Relating to the Protection of Victims of International Armed Conflicts art. 48, June 8, 1977, 1125 U.N.T.S. 3

Convention on the Prohibition of the Development, Production, Stockpiling and Use of Chemical Weapons and on their Destruction 1992

Protocol for the Prohibition of the Use of Asphyxiating, Poisonous or Other Gases, and of Bacteriological Methods of Warfare. Geneva, 17 June 1925

\section{Corresponding author}

Mohammad Saidul Islam can be contacted at: islamm.saidul@yahoo.com 